\title{
SISTEM PENDUKUNG KEPUTUSAN PEREKRUTAN ANGGOTA BEM MENGGUNAKAN METODE SAW DAN TOPSIS
}

\author{
Aziza Najar 1), Volvo Sihombing 2), Musthafa Haris Munandar 3) \\ 1,2,3Fakultas Sains dan Teknologi, Universitas Labuhanbatu \\ email: ${ }^{1}$ najarziza@gmail.com, ${ }^{2}$ volvolumbantoruan@gmail.com, ${ }^{3}$ harismunandaaar@gmail.com
}

\begin{abstract}
This study aims to solve problems in the recruitment of prospective BEM members at Labuhan Batu University. To select a competent member of the Labuhan Batu University Student Executive Board (BEM) organization, several stages of selection were carried out. However, decision making in recruitment is prone to collusion and nepotism at the student level on campus. To overcome this, a decision support system (DSS) for the recruitment of BEM members was designed using the SAW and TOPSIS methods. The DSS is designed using criteria, namely: GPA, Interview Score, Support Certificate, Organizational Experience and Commitment with weights for each criterion are 10,20,20,30,30.The result of this study is a decision support system using the TOPSIS method and SAW. The two best alternatives obtained from the ranking results using these two methods are alternatives with numbers $A 7$ and A8.
\end{abstract}

Keywords: Decision Support System, Selection, SAW, TOPSIS, Method

\section{PENDAHULUAN}

Civitas akademika merupakan entitas yang memiliki peran masing-masing dalam ruang lingkup universitas yang salah satunya adalah mahasiswa. Mahasiswa memiliki peran penting dalam keberlangsungan mengajar dan pembelajaran di kampus. Selain itu mahasiswa juga merupakan agent of exchange dalam gerakan pembaharuan. Melalui gerakan pembaharuan mahasiswa dilatih dalam mengembangkan kemampuan intelektual yang dimiliki untuk memandang segala sesuatu dengan positif, kritis, dan bertanggung jawab terhadap segala sesuatu hal. Selain hal tersebut mahasiswa juga di tuntut secara moril untuk bertanggung jawab terhadap akademik untuk menghasilkan sebuah karya yang berguna bagi orang banyak melalui berbagai hal.

Berdasarkan hal tersebut diperlukannya sebuah wadah kemahasiswaan yang berfungsi untuk merefleksikan berbagai gerakan dan kegiatan kemahasiswa. Wadah tersebut merupakan tempat untuk menyalurkan aspirasinya dan mengembangkan kemampuan kepemimpinan mahasiswa. Wadah tersebut berbentuk sebuah organisasi kemahasiswaan yang dipandang dapat mencapai tujuan yang ditetapkan sebelumnya. Organisasi kemahasiswan terdiri dari sekelompok orang (group of people) yang memiliki visi misi, keahlian, kreativitas dan berkerja sama untuk mencapai tujuan bersama, salah satunya adalah BEM (Badan Eksekutif Mahasiswa).

Demikian halnya dengan BEM Universitas Labuhan Batu memiliki fungsi sebagai sarana dan prasarana penunjang pendidikan pada tingkat universitas yaitu untuk mengembangkan soft skills. Beberapa peran penting soft skills diantaranya agar mahasiswa dapat meningkatkan kreativitas sebagai bekal masa depan untuk terjun langsung dalam menghadapi masalah yang ada dalam kehidupan bermasyarakat. Oleh sebab itu diperlukan seorang pemimpin dan anggota yang berkompeten agar dapat mengelola serta mengatur jalannya sebuah organisasi untuk mencapai tujuan yang ditetapkan bersama.

Pemimpin dan anggota organisasi pada BEM Universitas Labuhan Batu yang berkompeten berasal dari pemilihan yang dilakukan setiap tahunnya dalam satu periode, khususnya pada pemilihan anggota pengurus dilakukan dengan beberapa tahapan seleksi. Seleksi tersebut terdiri dari seleksi berkas dan 
seleksi wawancara seleksi, lalu kemudian dibuat keputusan penerimaan dengan musyawarah yang dilakukan oleh pengurus organisasi pada periode sebelumnya. Pada tahap ini, pengambilan keputusan yang dilakukan sangat rawan terjadinya praktik kolusi dan nepotisme tingkat kampus. Penentuan keputusan yang tidak transparan sering terjadi, seperti calon anggota yang memiliki kedekatan dengan pengurus organisasi sebelumnya bisa mendapatkan peluang lolos seleksi lebih besar dibandingkan calon lainnya.

Berdasarkan latar belakang tersebut, untuk mempermudah pemilihan calon anggota BEM pada BEM Universitas Labuhan Baru, maka dirancang sebuah sistem pendukung keputusan yang terkomputerisasi yang dapat digunakan untuk mempermudah pemilihan perangkingan terhadap calon anggota BEM tersebut sehingga dapat dipilih calon-calon terbaik sebagai anggota BEM pada periode tahun yang baru.

Dalam perkembangan dunia yang memasuki era globalisasi ini, peranan teknologi informasi sangatlah dibutuhkan untuk mempermudah pengolahan data [1]-[8] dan juga untuk membantu dalam pengambilan keputusan. Sistem pendukung keputusan saat ini telah dimanfaatkan memfasilitasi berbagai pemecahan masalah [9]-[13], [14]-[17]. Metode yang dipilih untuk diterapkan dalam sistem pendukung keputusan pemilihan calon anggota BEM ini adalah dengan menggunakan metode TOPSIS (Technique for Order Performance by Similarity to Ideal Solution) dan metode SAW (Simple Additive Weigthing). Metode TOPSIS dan SAW merupakan metode pengambilan keputusan multi kriteria dengan menerapkan bobot skor pada masing-masing kriteria [18], [19], [20], [21], [22].

\section{METODE PENELITIAN}

Adapun tahapan yang dilakukan dalam Perancangan sistem pendukung keputusan perekrutan anggota BEM menggunakan metode saw dan topsis ini dilakukan dengan tahapan seperti yang terdapat pada gambar 1. Kriteria yang digunakan serta bobot dari setiap masingmasing kriteria dalam perekrutan anggota BEM Universitas Labuhan Batu ini dapat dilihat pada tabel 1.

Table 1. Kriteria dan Bobot

\begin{tabular}{clc}
\hline Kode & \multicolumn{1}{c}{ Kriteria } & Bobot \\
\hline C1 & IPK & 4 \\
C2 & Nilai Wawancara & 5 \\
C3 & Sertifikat Pendukung & 3 \\
C4 & Pengalaman & 2 \\
C5 & Berorganisasi & \\
\hline
\end{tabular}

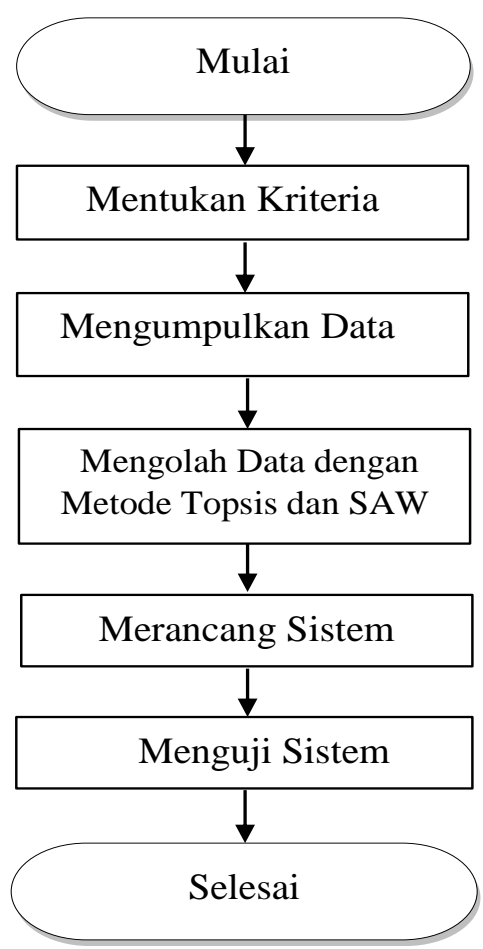

Gambar 1. Framework Penelitian

Pada gambar 1 dapat dilihat tahapan perancangan SPK perekrutan BEM ini dimulai dari penentuan kriteria dan bobot setiap kriteria. Kemudian dilanjutkan dengan merancang sistem pendukung keputusan yang mampu mengolah data yang telah dikumpulkan dengan menggunakan metode Topsis dan SAW.

\section{HASIL DAN PEMBAHASAN}

Penentuan kriteria dan bobot untuk setiap kriteria serta penginputan data alternatif yang diolah dalam perancangan sistem pendukung 
keputusan perekrutan anggota BEM menggunakan metode saw dan topsis ini, terdapat pada gambar 2 sampai dengan gambar 5 .

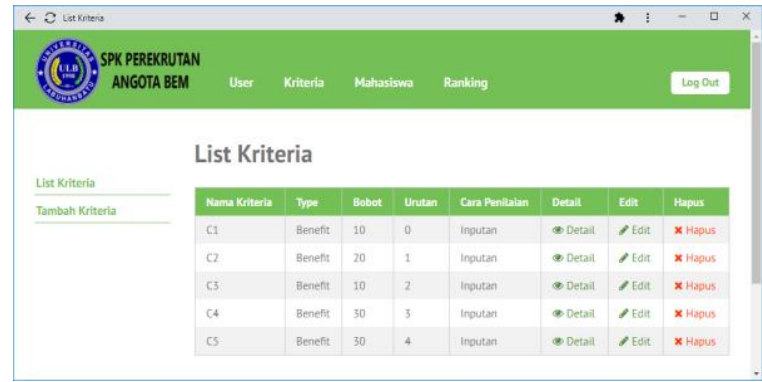

Gambar 2. Data Kriteria

Untuk menambah Kriteria dapat dilakukan dengan mengklik menu Tambah Kriteria pada menu Kriteria seperti pada gambar 3.

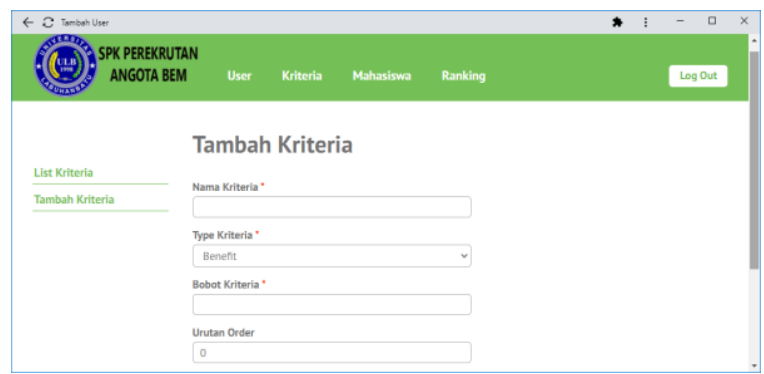

Gambar 3. Tambah Kriteria

Untuk menambah data alternatif mahaiswa yang akan direkrut dapat dilakukan dengan menggunakan Menu Mahasiswa. Tampilan List Mahasiswa dapat dilihat pada gambar 4.

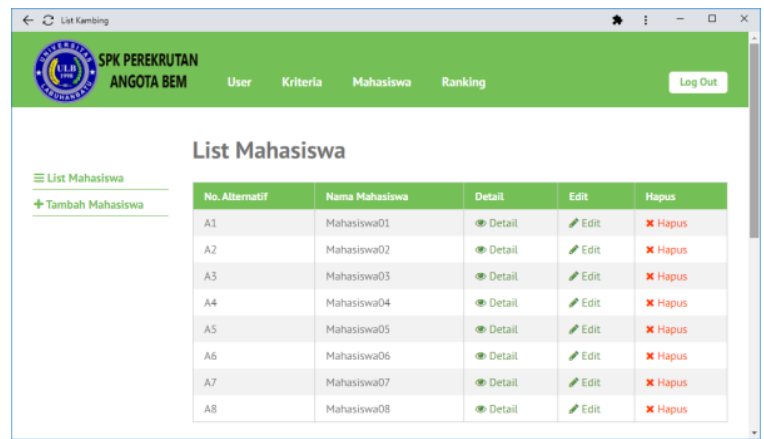

Gambar 4. Data Alternatif

Untuk menambah data mahasiswa yang akan direkrut dapat dilakukan dengan memilih menu Tambah Mahasiswa pada menu Mahasiswa seperti terdapat pada gambar 5 .

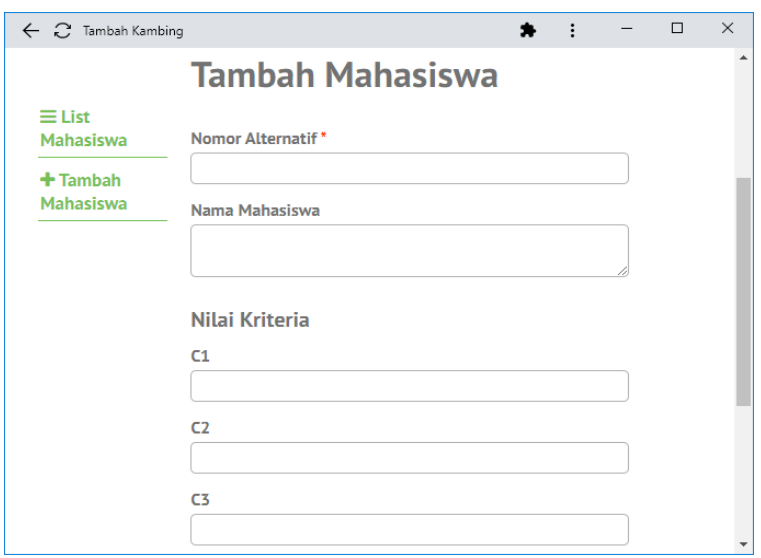

Gambar 5. Data Alternatif

\subsection{Perankingan dengan Metode Topsis}

Selanjutnya untuk melihat matriks keputusan yang akan diolah dengan menggunakan Metode Topsis dapat dilakukan dengan memilih menu Rangking dilanjutkan dengan memilih menu Topsis. Setelah itu akan ditampilkan Matriks Keputusan seperti pada gambar 5.

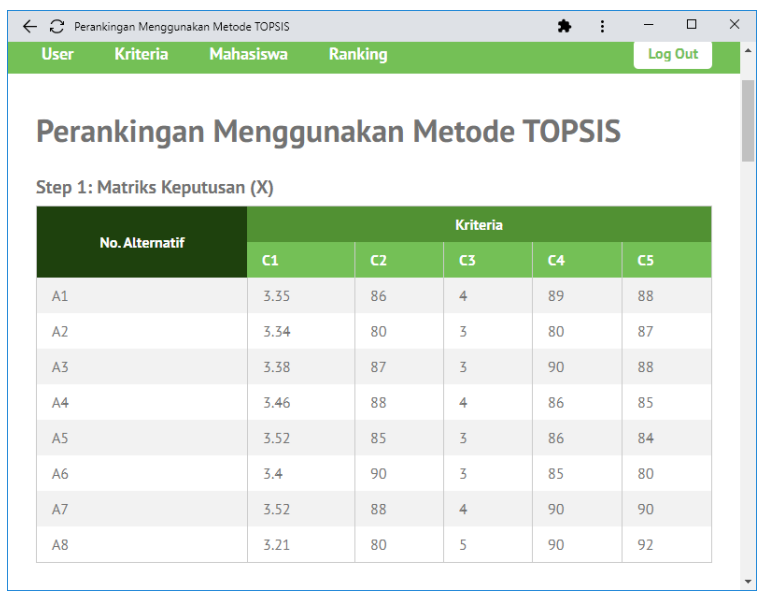

Gambar 5. Matriks Keputusan

Selanjutnya akan ditampilkan bobot preferensi dari setiap kriteria.

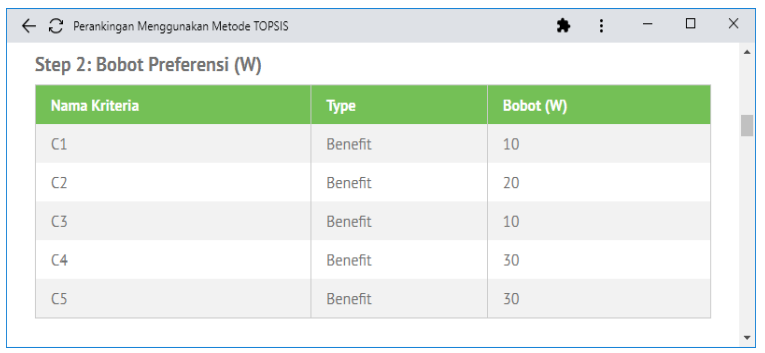

Gambar 6. Bobot Preferensi 
Langkah berikutnya, sistem akan menampilkan Matriks Ternormalisasi (R) seperti terdapat pada gambar 7.

\begin{tabular}{|c|c|c|c|c|c|c|}
\hline \multicolumn{4}{|c|}{$\leftarrow \approx$ Perankingan Menggunakan Metode TOPSIS } & * & $-\quad$ & $x$ \\
\hline \multicolumn{7}{|c|}{ Step 3: Matriks Ternormalisasi (R) } \\
\hline \multirow{2}{*}{ No. Alternatif } & \multicolumn{5}{|c|}{ Kriteria } & \\
\hline & $\mathrm{C}_{1}$ & $\mathrm{C}_{2}$ & C3 & C4 & C5 & \\
\hline $\mathrm{A} 1$ & 0.3485 & 0.3553 & 0.3831 & 0.3614 & 0.3584 & \\
\hline A2 & 0.3474 & 0.3305 & 0.2873 & 0.3249 & 0.3543 & \\
\hline A3 & 0.3516 & 0.3595 & 0.2873 & 0.3655 & 0.3584 & \\
\hline A4 & 0.3599 & 0.3636 & 0.3831 & 0.3492 & 0.3461 & \\
\hline A5 & 0.3662 & 0.3512 & 0.2873 & 0.3492 & 0.3421 & \\
\hline A6 & 0.3537 & 0.3719 & 0.2873 & 0.3452 & 0.3258 & \\
\hline A7 & 0.3662 & 0.3636 & 0.3831 & 0.3655 & 0.3665 & \\
\hline A8 & 0.3339 & 0.3305 & 0.4789 & 0.3655 & 0.3746 & \\
\hline
\end{tabular}

Gambar 7. Matriks Ternormalisasi (R)

Setiap data yang terdapat pada matriks di atas dikalikan berdasarkan bobot setiap kriteria, dengan hasil sebagai Matriks Y seperti pada gambar 8 .

\begin{tabular}{|c|c|c|c|c|c|c|}
\hline$\leftarrow \circlearrowright$ Perankingan Mengg & an Metode & & & $\star$ & $\vdots \quad-$ & $x$ \\
\hline Step 4: Matriks Y & & & & & & \\
\hline & & & Krit & & & \\
\hline & C1 & $\mathrm{C}_{2}$ & C3 & C4 & C5 & \\
\hline A1 & 3.4847 & 7.1066 & 3.8313 & 10.8427 & 10.7507 & \\
\hline A2 & 3.4743 & 6.6108 & 2.8735 & 9.7463 & 10.6286 & \\
\hline A3 & 3.5159 & 7.1892 & 2.8735 & 10.9646 & 10.7507 & \\
\hline A4 & 3.5991 & 7.2719 & 3.8313 & 10.4772 & 10.3842 & \\
\hline A5 & 3.6615 & 7.024 & 2.8735 & 10.4772 & 10.2621 & \\
\hline A6 & 3.5367 & 7.4371 & 2.8735 & 10.3554 & 9.7734 & \\
\hline A7 & 3.6615 & 7.2719 & 3.8313 & 10.9646 & 10.9951 & \\
\hline A8 & 3.3391 & 6.6108 & 4.7891 & 10.9646 & 11.2394 & \\
\hline
\end{tabular}

Gambar 8. Matrix Y

Kemudian, selanjutnya sistem akan menampilkan nilai Solusi Ideal Positif (A+) dan Solusi Ideal Negatif (A-) seperti yang terdapat pada gambar 9 .

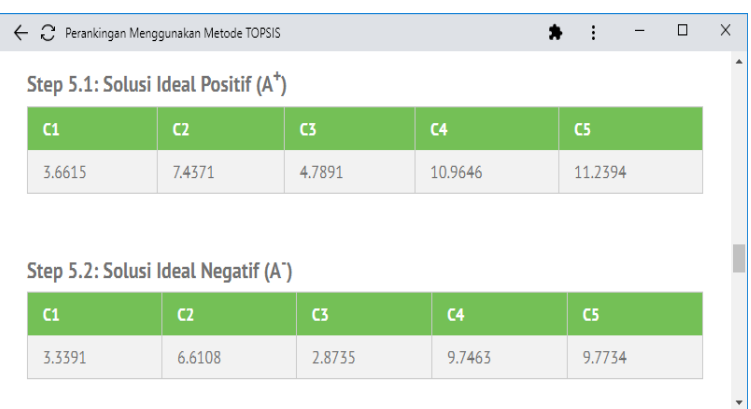

Gambar 9. Solusi Ideal Positif (A+)

Tahap berikutnya sistem akan menampilkan Jarak Ideal Positif ( $\mathrm{Si}+$ ) dan Jarak Ideal Negatif ( $\mathrm{Si}$-) seperti yang ditampilkan pada gambar 10 dan gambar 11.

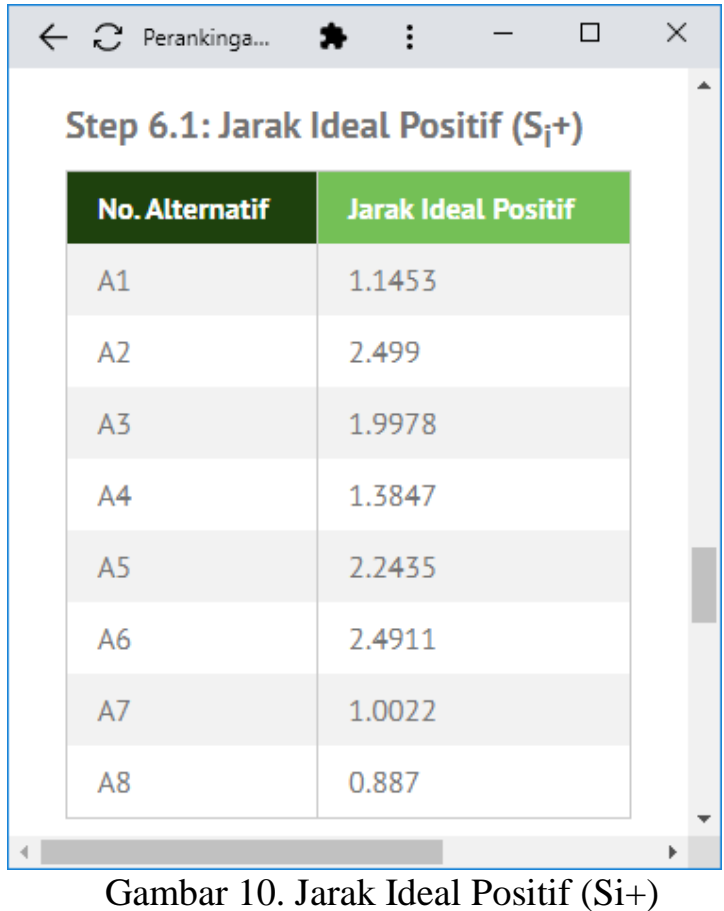

Jarak Ideal Negatif (Si-)

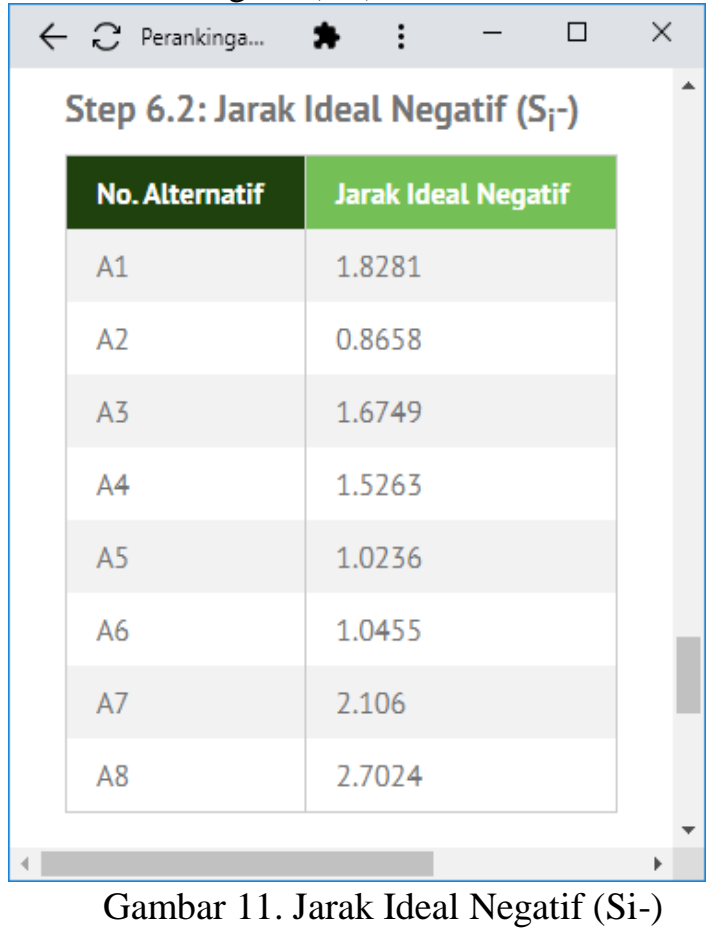


Setelah semua tahap tersebut dilewat, maka hasil akhir dari pengolah SPK dengan metode Topsis dihasilkan berupa hasil Perangkingan (V) seperti yang terdapat pada gambar 12.

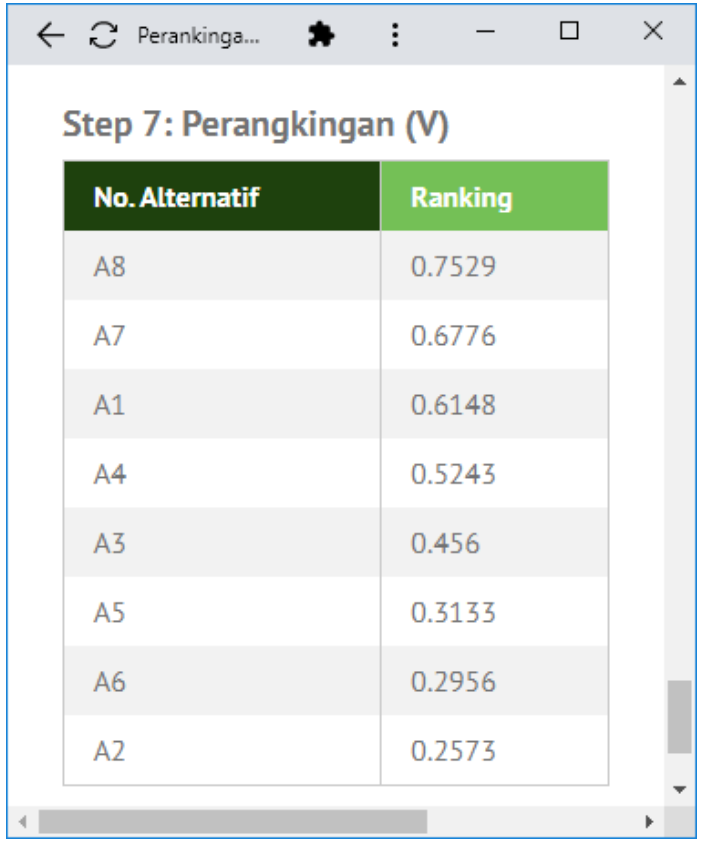

Gambar 12. Hasil Perangkingan (V) dengan menggunakan Metode Topsis

\subsection{Pengolahan data dengan Metode SAW}

Untuk mengolah data perekrutan anggota BEM dengan menggunakan SPK Metode SAW gunakan menu Ranking dan selanjutnya pilih menu SAW seperti pada gambar 13.

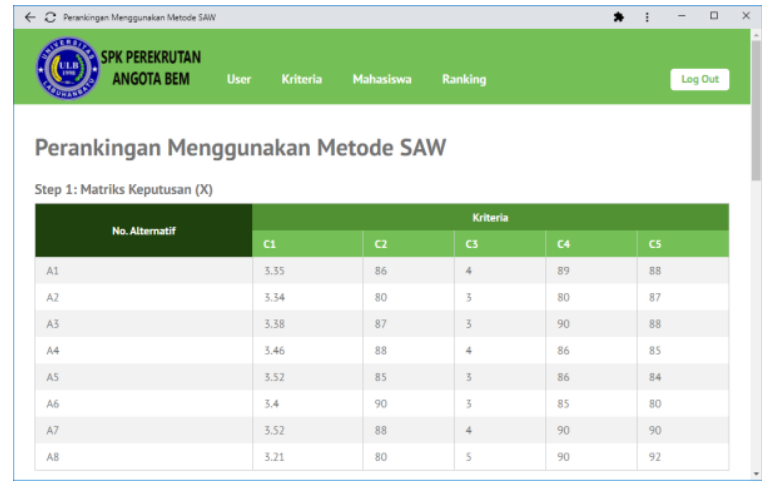

Gambar 13. Perankingan Menggunakan Metode SAW

Selanjutnya akan ditampilkan Bobot Preferensi (W) untuk setiap kriteria seperti pada gambar 14 .

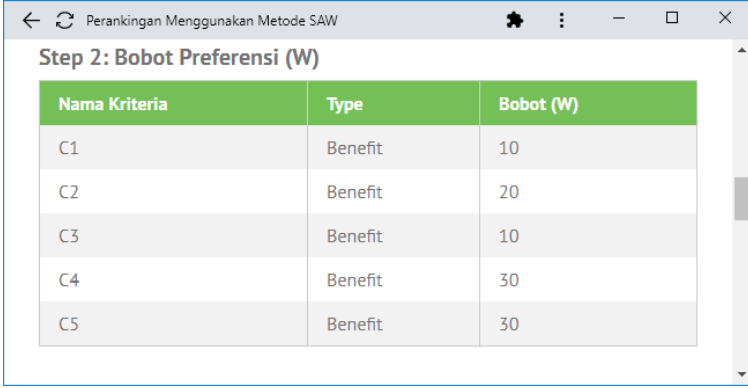

Gambar 14. Bobot Preferensi (W)

Tahap berikut nya ditampilkan hasil dari Matriks Ternormalisasi (R) seperti pada gambar 15.

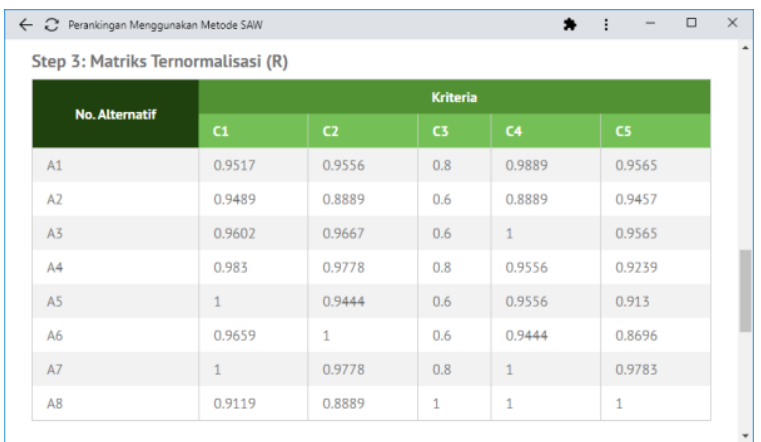

Gambar 15. Matriks Ternormalisasi (R)

Tahap berikutnya ditampilkan hasil pengolahan SPK dengan metode SAW dalam bentuk Perangkingan (V) seperti pada gambar 16.

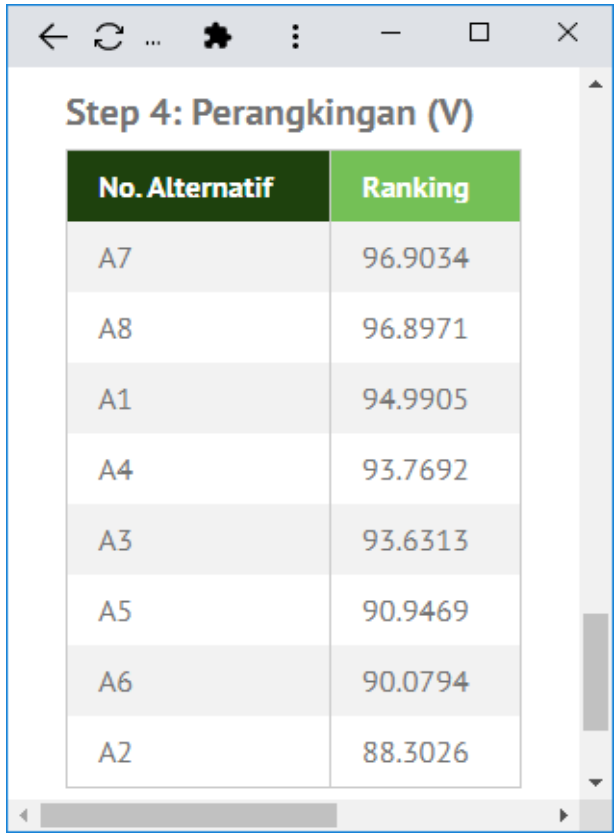

Gambar 16. Hasil Perangkingan Metode SAW 


\section{KESIMPULAN}

Berdasarkan hasil perancangan sistem pendukung keputusan perekrutan anggota BEM menggunakan metode saw dan topsis dapat disimpulkan bahwa penggunaan sistem ini dapat mempermudah BEM dalam melakukan perangkingan perekrutan anggota BEM dengan cepat dan efisien. SPK ini menggunakan metode Topsis dan SAW dengan kriteria yang terdiri IPK, Nilai Wawancara, Sertifikat Pendukung, Pengalaman Berorganisasi, Komitmen.

\section{REFERENSI}

[1] V. M. M. Siregar, E. Damanik, M. R. Tampubolon, E. I. Malau, E. P. S. Parapat, and D. S. Hutagalung, "Sistem Informasi Administrasi Pinjaman (Kredit) Pada Credo Union Modifikasi (CUM) Berbasis Web," J. Tekinkom, vol. 3, no. 2, pp. 6269, 2020.

[2] H. Sugara, E. Sirait, M. A. Hanafiah, and N. F. Siagian, "Sistem Informasi Pembayaran SPP Pada SMK Swasta Teladan Tanah Jawa Menggunakan Vb.Net," J. Tek. Inf. dan Komput., vol. 3, no. 1, p. 14, 2020.

[3] S. S. S, A. T. Purba, and V. M. M. Siregar, "Sistem Pendukung Keputusan Kelayakan Pemberian Pinjaman Kredit Menggunakan Metode Topsis Pada Cum Caritas HHKBP Pematangsiantar," J. Tek. Inf. dan Komput., vol. 3, no. 1, p. 1, Sep. 2020.

[4] A. T. Purba and V. M. M. Siregar, "Sistem Penyeleksi Mahasiswa Baru Berbasis Web Menggunakan Metode Weighted Product," TEKINKOM, vol. 3, no. 1, pp. $1-8,2020$.

[5] S. P. Tamba, M. D. Batubara, W. Purba, M. Sihombing, V. M. Mulia Siregar, and J. Banjarnahor, "Book data grouping in libraries using the k-means clustering method," J. Phys. Conf. Ser., vol. 1230, no. 1, p. 012074, Jul. 2019.
[6] V. M. M. Siregar, H. Sugara, and G. A. Purba, "Aplikasi Pencatatan Laporan Penjualan Kita-Kita.Net Berbasis Web," TEKINKOM, vol. 2, no. 1, pp. 80-86, 2019.

[7] V. M. M. Siregar, H. Sugara, and I. M. Siregar, "Perancangan Sistem Informasi Pendataan Barang Pada PT. Serdang Hulu," J. Comput. Bisnis, vol. 12, no. 2, pp. 111-117, 2018.

[8] V. M. Siregar and H. Sugara, "Perancangan Dan Implementasi Aplikasi Penggajian Berbasis Dekstop Pada Murni Sadar English Course," J. Tek. Inf. dan Komput., vol. 1, no. 2, pp. 42-48, 2018.

[9] Mesran, G. Ginting, Suginam, and R. Rahim, "Implementation of Elimination and Choice Expressing Reality ( ELECTRE ) Method in Selecting the Best Lecturer ( Case Study STMIK BUDI DARMA )," Int. J. Eng. Res. Technol. (IJERT, vol. 6, no. 02, pp. 141-144, 2017.

[10] M. Sevkli, "An application of the fuzzy ELECTRE method for supplier selection," Int. J. Prod. Res., vol. 48, no. 12, pp. 3393-3405, Jun. 2010.

[11] K. M. A. S. Al-Harbi, "Application of the AHP in project management," Int. J. Proj. Manag., vol. 19, no. 1, pp. 19-27, 2001.

[12] Angelina et al., "Application Selection Lending Houses Subsidized by the Method of AHP and SAW," J. Phys. Conf. Ser., vol. 1230, p. 012082, Jul. 2019.

[13] D. Bambang, T. Wijaya, T. Wahyono, and A. N. S. Hapsari, "TOPSIS Method Implementation for Employee Performance Information System," Int. J. Inf. Technol. Bus., vol. 2, no. 1, pp. 21-26, 2019.

[14] V. M. M. Siregar and H. Sugara, "Implementation of artificial neural network to assesment the lecturer's performance," IOP Conf. Ser. Mater. Sci. 
Eng., vol. 420, p. 012112, Oct. 2018.

[15] V. M. M. Siregar, M. R. Tampubolon, E. P. S. Parapat, E. I. Malau, and D. S. Hutagalung, "Decision support system for selection technique using MOORA method," IOP Conf. Ser. Mater. Sci. Eng., vol. 1088, no. 1, p. 012022, Feb. 2021.

[16] V. M. M. Siregar et al., "Implementation of ELECTRE Method for Decision Support System," IOP Conf. Ser. Mater. Sci. Eng., vol. 1088, no. 1, p. 012027, Feb. 2021.

[17] V. Sihombing, V. M. M. Siregar, W. S. Tampubolon, M. Jannah, Risdalina, and A. Hakim, "Implementation of simple additive weighting algorithm in decision support system," IOP Conf. Ser. Mater. Sci. Eng., vol. 1088, no. 1, p. 012014, Feb. 2021.

[18] J. Simatupang, "Sistem Pendukung Keputusan Penentuan Karyawan Terbaik Menggunakan Metode Saw Studi Kasus Amik Mahaputra Riau," J. Intra-Tech, vol. 2, no. 1, pp. 73-82, 2018.

[19] S. P. Tamba, P. Wulandari, M. Hutabarat, M. Christina, and A. Oktavia, "PENGGUNAAN METODE TOPSIS (TECHNIQUE FOR ORDER PREFERENCE BY SIMILARITY TO IDEAL SOLUTION) UNTUK MENENTUKAN KUALITAS BIJI KOPI TERBAIK BERBASIS ANDROID," $J$. Mantik Penusa, vol. 3, no. 1, pp. 73-81, 2019.

[20] V. M. M. Siregar, S. Sonang, A. T. Purba, H. Sugara, and N. F. Siagian, "Implementation of TOPSIS Algorithm for Selection of Prominent Student Class," J. Phys. Conf. Ser., vol. 1783, no. 1, p. 012038, Feb. 2021.

[21] R. O. S. Gurning, W. Busse, and M. Lubnan, "Decision Making of Full Speed, Slow Steaming, Extra Slow Steaming and Super Slow Steaming using TOPSIS, " Int.
J. Mar. Eng. Innov. Res., vol. 2, no. 1, 2017.

[22] A. Azizi, D. O. Aikhuele, and F. S. Souleman, "A Fuzzy TOPSIS Model to Rank Automotive Suppliers," Procedia Manuf., vol. 2, no. February, pp. 159-164, 2015. 